\title{
A prospective study of rock climbing injuries
}

\author{
Jonathan P Wyatt, Gordon W McNaughton, Patrick T Grant
}

\begin{abstract}
Objectives-To study the rate, causes, and nature of rock climbing injuries presenting to an accident and emergency (A\&E) department.

Methods-Patients presenting with rock climbing injuries to an urban A\&E department were studied prospectively for one year.

Results-19 rock climbers presented during the year, at a rate of one per 2774 A\&E attendances. Fourteen climbers were injured on outdoor cliffs and five on the local indoor climbing wall, where the safety mats were noted to be in poor condition. Eighteen climbers had been injured during falls, 17 hitting the ground. Twelve of these climbers sustained fractures, four of which were missed on initial attendance. The remaining climber sustained the characteristic A2 pulley finger injury, which was treated conservatively with a good result.

Conclusions-The risks of rock climbing in Britain would be reduced if lead climbers arranged protection at earlier stages of climbs. Sports centres with climbing walls should regularly inspect and repair their safety equipment. It is important for staff in A\&E departments to appreciate the large forces involved in any climbing fall, in order that significant injuries are not missed. Those treating injured climbers should also be aware of the specific injuries to which elite climbers are predisposed.
\end{abstract}

(Br F Sports Med 1996;30:148-150)

Key terms: rock climbing; injury; accident and emergency department

Since the publication of the first rock climbing guidebook in 1894, rock climbing has developed into an acrobatic and sophisticated sport, enjoyed by hundreds of thousands of people all over the world. ${ }^{1}$ The principles of rock climbing are straightforward. Progress is achieved using who have not yet arranged "protection", or climbers not using ropes at all, will obviously fall to the ground if they slip. The second climber

has the security and safety of a rope from the leader above. Once the team reaches the top of a cliff they can either abseil back down the rope, or walk down the side to the bottom.

In view of its popularity and the obvious potential for injury, it is surprising that there is little published information regarding injuries sustained while rock climbing in Britain. This is the first prospective study of rock climbing injuries presenting to an accident and emergency $(\mathrm{A} \& \mathrm{E})$ department.

\section{Methods}

Patients presenting to one $A \& E$ department with injuries sustained while rock climbing were studied prospectively for one year (November 1992 to October 1993).

\section{Results}

Nineteen patients, 15 men and four women, with a mean age of 29 years, presented with rock climbing injuries out of 52697 new attendances (a rate of one per 2774 new patients). Fourteen climbers had injured themselves climbing on outdoor cliffs and five while practising their skills on the local indoor climbing wall. Eighteen of the 19 climbers had sustained their injuries during falls, of between three and 40 feet (table 1). The remaining climber, who was the only elite climber among those presenting, had not actually fallen. He complained of a painful left ring finger after his foot had slipped while pulling up on a tiny fingerhold, resulting in most of his body weight being taken by the finger. Examination revealed tender swelling at the proximal interphalangeal joint, with bowstringing of the flexor tendon, indicating rupture of the $\mathrm{A} 2$ pulley. He was treated conservatively with several weeks rest and was able to return to "extreme" rock climbs after two months, using tape to protect his finger.

Twelve patients had fractures, the remaining seven had soft tissue injuries (table 2). Three fractures required internal fixation: one unstable

\section{Table 1 Mechanism of injuries of the 19 climbers}

Fall to the ground
Fall hitting rockface, but held by rope
Fall whilst abseiling
Injury while pulling up (no fall)

Table 2 The injuries

\section{Fractures}

Distal fibula fractures

Calcaneal fracture

Scaphoid fractures

Tumbar spine

Tibial fracture

Maisonneuve fracture

Soft tissue injuries

Ankle injuries

Knee injury

Back injury

Hand injury

A2 pulley finger injury fingerholds and footholds, without pulling on the rope or using other aids. The team, usually comprising two climbers, starts at the bottom of a cliff and climbs up by a predetermined route. Leading climbers trail a rope, threading it through equipment placed to provide "protection", such that, if they slipped they might fall a few feet but would hope to be prevented from hitting the ground by the second climber holding the rope ("belaying"). ${ }^{2}$ Leading climbers in the initial stages of a climb 


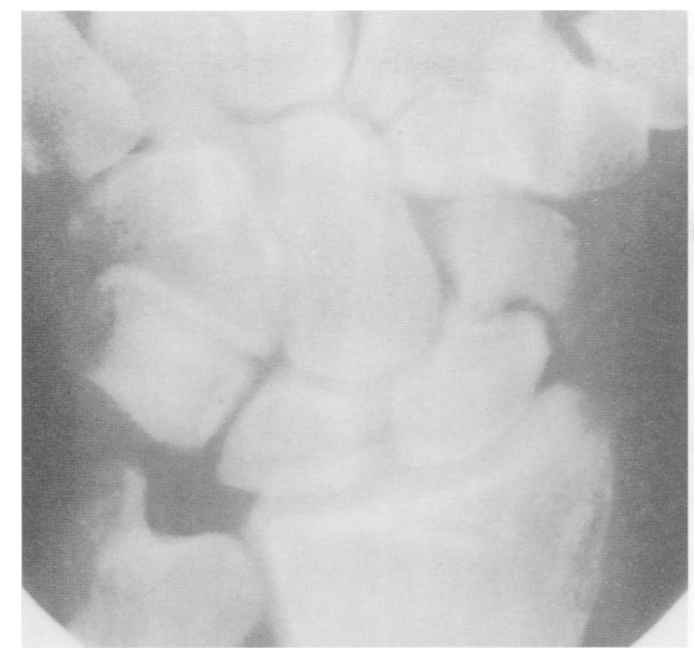

Figure 1 Non-union of this missed scaphoid fracture required internal fixation.

lumbar spine fracture, one Maisonneuve fracture, and one scaphoid fracture. All limb fractures and two of the soft tissue injuries required immobilisation in plaster of Paris. Four of the 12 fractures were "missed" on initial attendance at various $A \& E$ departments. All four missed fractures required immobilisation and one (a scaphoid fracture missed at another hospital two weeks previously) developed nonunion, requiring surgery (fig 1 ).

\section{Discussion}

As with many other British cities, Glasgow is relatively devoid of nearby quality climbing cliffs, no doubt partly accounting for the relatively low presentation rate of injured climbers. Despite this, it is notable that the majority of climbers who presented to this A\&E department had fractures or significant injuries. Although there are some well documented examples of survival without injury after long falls, it is recognised that the severity of injury is related to the length of the fall. ${ }^{3}{ }^{4}$ The fractures were typical of those that one might expect following falls, particularly those of the calcaneum (fig 2) and upper lumbar spine: injuries with significant long term sequelae. ${ }^{5} 6$

Evidence from the United States has shown that head injuries are the leading cause of death in both mountaineering and rock climbing. ${ }^{78}$ All patients presenting to $A \& E$ in this series survived: none had a head injury. This does not

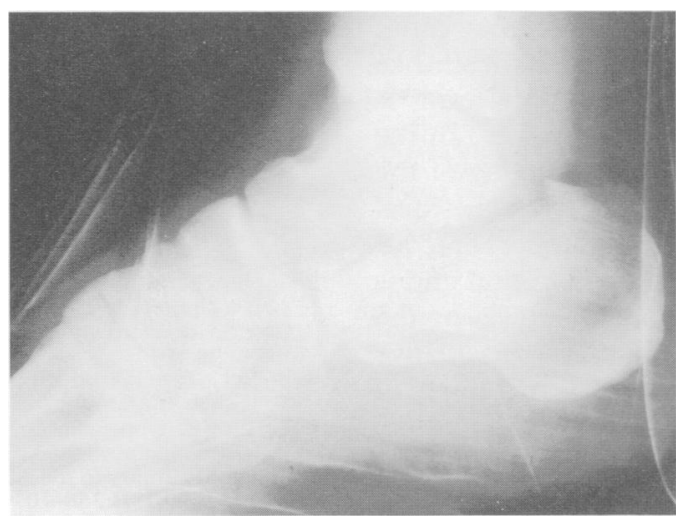

Figure 2 This calcaneal fracture resulted from a 40 foot fall to the ground. reflect a different pattern of injury; rather, it is almost certainly due to the fact that many rock climbers with fatal head injuries in Britain die before reaching hospital. In keeping with data from the United States, most of the rock climbers in this study sustained their injuries as a result of falls while leading, with lower extremity injuries predominating. ${ }^{7}$ In contrast to the experience reported in Yosemite, the majority of "leader falls" in this study culminated in impact with the ground, rather than against the rock face after being saved by the rope. ${ }^{7}$ This no doubt reflects the fact that climbs in Britain tend to be much shorter than in Yosemite, with climbers therefore spending more of their time climbing just above the ground. It remains commonplace for British leaders not to consider arranging protection in the first 20 feet of a climb (fig 3), yet falls from well below this may cause significant injuries. The problem stems from the fact that exposure is limited within the first part of a climb. As a result, climbers' perception of danger is irrationally distorted, such that they feel safe where they are clearly far from safe. Rock climbers need to be strongly encouraged to arrange protection within the initial stages of climbs. This would prevent many injuries.

Ever since the famous tragedy during the first ascent of the Matterhorn in 1865, in which four climbers died when the rope broke, mountaineers and rock climbers have been very concerned about equipment failure. ${ }^{9}$ Advances in both climbing equipment and technique have lessened the acknowledged potential risks to both climber and belayer. ${ }^{10}$ It is reassuring that no accidents in this study resulted from equipment failure, which now appears to be very unusual. ${ }^{11}$ However, examination of the "crash mats" at the bottom of the indoor climbing wall showed them to be old and in a

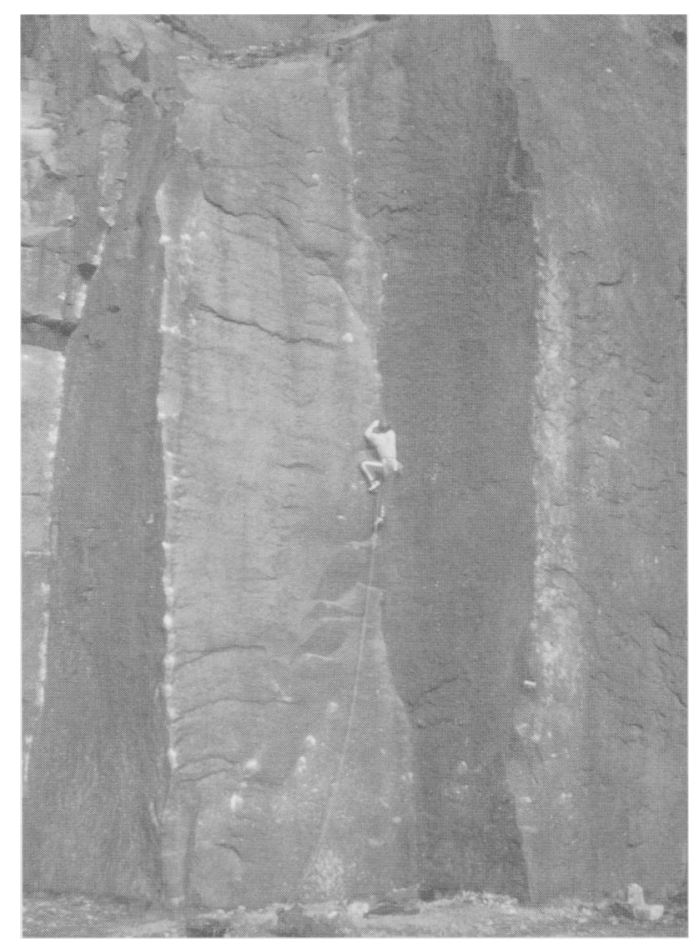

Figure 3 Lead climbers are at considerable risk until the first protection is arranged. 


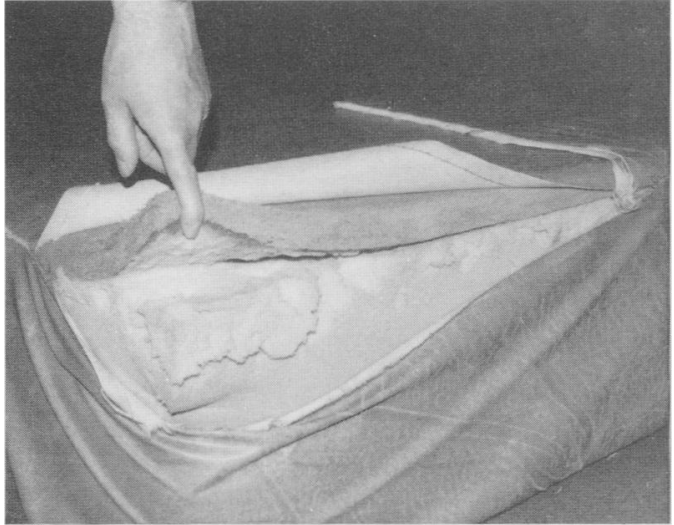

Figure 4 The safety mats at the indoor climbing wall need repair.

poor state of repair (fig 4). As with most indoor walls, although there is provision to allow practice with a safety rope from above, the vast majority of climbers prefer to climb unroped and rely upon the crash mats when, as frequently happens, an overambitious move fails. It would be sensible for all sports centres with indoor climbing walls to review and where necessary, repair and replace damaged mats.

It has been recognised that there are specific injuries associated with rock climbing and training for rock climbing. ${ }^{12}$ It is important that those involved in providing treatment for injured rock climbers be aware of these injuries and their management. Some common problems, such as splitting of fingertip skin pads (partly due to wear and tear and partly to the chalk used to improve grip), may be relatively minor and self limiting. ${ }^{13}$ Other problems may be more complex and difficult to diagnose. In particular, it is emerging that the relatively small but growing group of elite full time climbers in the United Kingdom is particularly prone to finger injuries, some of which appear to be unique to the sport. ${ }^{14}{ }^{15}$ The one elite climber in this series sustained an injury to his left ring finger flexor tendon sheath at the proximal interphalangeal joint when his foot slipped as he pulled up on a small one fingerhold. This injury, which has been termed the A2 pulley injury, was only first described in 1990 and appears to be unique to rock climbers. ${ }^{16}$ It is easy to understand how the injury may occur, considering the huge forces involved as a climber pulls up on a finger flexed at the proximal interphalangeal joint (fig 5). Any sudden additional force, perhaps due to the climber's foot slipping as in this case, may cause the flexor tendon to cut through its sheath like a cheesewire. The result in the short term, is pain and swelling around the A2 pulley. In the long term, there is obvious bowstringing of the flexor tendon. It is not yet clear what the ideal treatment of this injury is. Surgical reconstruction has been proposed as an option and is certainly technically feasible. ${ }^{14}{ }^{17}$ However, the patient in this study shows that conservative treatment, comprising rest and firm taping of the finger, may have a satisfactory outcome. Further study of this injury is required.

Perhaps the lack of experience of A\&E staff dealing with rock climbers, plus the stoical nature of these sportsmen accustomed to

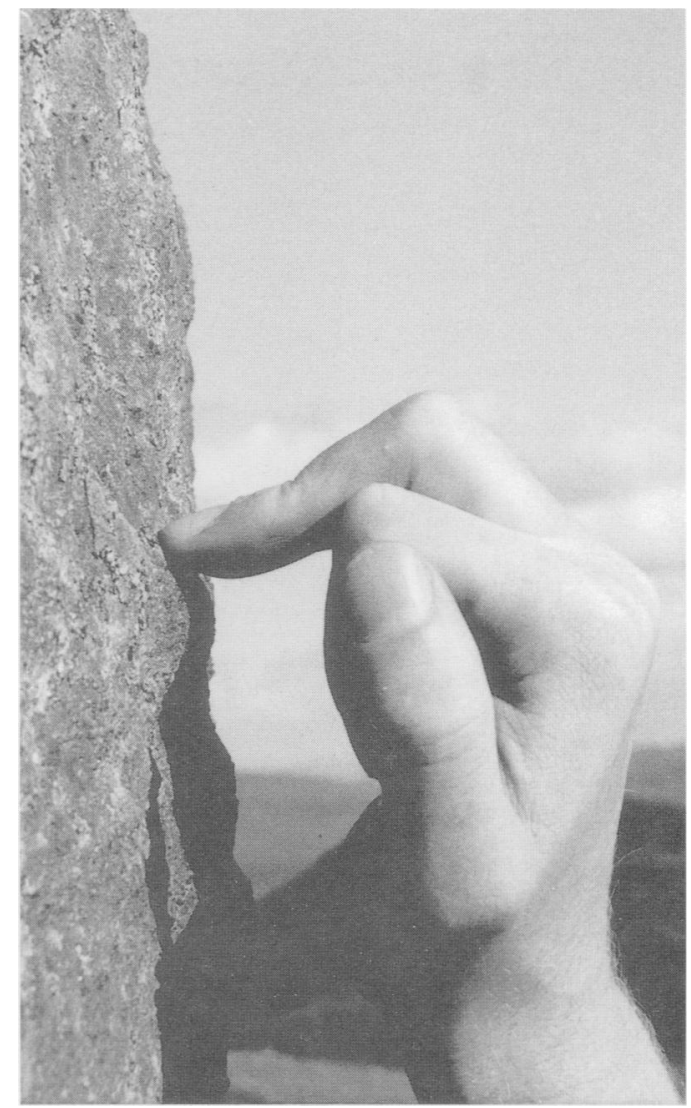

Figure 5 Small holds risk the A2 pulley.

minor injuries, results in underestimation of their injuries, accounting for the high rate of missed fractures. The missed or late diagnosis of fractures may have unfortunate consequences, as illustrated by the patient in this series who required internal fixation to treat non-union of his missed scaphoid fracture. $\mathrm{A} \& \mathrm{E}$ doctors should be aware of the large forces involved in any rock climbing fall and be suspicious of significant injury.

1 Haskett-Smith WP. Climbing in the British Isles, volume 1 . England. London: Longmans, Green, 1894.

2 Fawcett R, Lowe J, Nunn P, Rouse A. Climbing. London: Bell and Hymen, 1986.

3 de Haven $\mathrm{H}$. Mechanical analysis of survival in falls from heights of fifty to one hundred and fifty feet. War Med 1942;2:586-96.

4 Steedman DJ. Severity of free-fall injury. Injury 1989; 20:259-61.

5 Scalea T, Goldstein A, Phillips T, Sclafani SJA, Panetta T, McAuley J, et al. An analysis of 161 falls from a height: the 'Jumper Syndrome'. $\mathcal{F}$ Trauma 1986;26:706-12.

6 Mathis RD, Levine SH, Phifer S. An analysis of accidental free falls from a height: the 'Spring break' syndrome. $\mathcal{F}$ Trauma 1993;34:123-6.

7 Bowie WS, Hunt TK, Allen HA. Rock-climbing injuries in Yosemite National Park. West fु Med 1988;149:172-7.

8 Addiss DG, Baker SP. Mountaineering and rock-climbing injuries in US National Parks. Ann Emerg Med 1989; 18:975-9.

9 Whymper E. Scrambles amongst the Alps in the years 1860-1869. London: Thomas Nelson and Sons, 1871.

10 Butlin PA. Potential injury mechanisms to the climber's belayer. Br $\mathcal{F}$ Sports Med 1985;19:188-91.

11 Schussman LC, Lutz LJ. Mountaineering and rock climbing accidents. Physician Sports Med 1982;10(6):52-61.

12 Bannister P, Foster P. Upper limb injuries associated with rock climbing. Br $\mathcal{F}$ Sports Med 1986;20:55.
ronister P, Foster P. Uper limb injuries

13 Cole AT. Fingertip injuries in rock climbers. Br 7 Sports Med 1990;24:14

14 Bollen SR, Gunson CK. Hand injuries in competition climbers. Br f Sports Med 1990;24:16-18.

15 Bollen SR. Upper limb injuries in elite rock climbers. $7 R$ Coll Surg Edinb 1990;35(suppl):S18-20.

16 Bollen SR. Injury to the A2 pulley in rock climbers. $f$ Hand Surg 1990;15B:268-70.

17 Lin GT, Amadio PC, An KN, Cooney WP, Chao EYS Biomechanical analysis of finger flexor pulley reconstruction. $\mathcal{F}$ Hand Surg $1989 ; 14 \mathbf{B}: 278-82$. 